\title{
Effects of Nearby Nature on Urban Children's Stress
}

\author{
José A. Corraliza, Silvia Collado, Lisbeth Bethelmy \\ Faculty of Psychology, \\ Universidad Autónoma de Madrid,, Spain \\ josea.corraliza@uam.es
}

\begin{abstract}
The study shows empirical evidence of the moderator effect that school and nearby nature at home has on children. A total of 172 children were interviewed and data about their stress level, the amount of nature they perceived around them and frequency of exposure to adversity, was collected. The nearby nature at home and in the school for each of the children was measured using a designed scale. The results suggest that nature bolsters children's resilience so that those children who have more contact with nature cope better with adversity than those who do not have daily access to nature.
\end{abstract}

Keywords: Nature, Children, Moderator Effect, Stress

eISSN 2514-751X @ 2017 The Authors. Published for AMER ABRA by e-International Publishing House, Ltd., UK.. This is an open access article under the CC BY-NC-ND license (http://creativecommons.org/licenses/by-ncnd/4.0/). Peer-review under responsibility of AMER (Association of Malaysian Environment-Behaviour Researchers), ABRA (Association of Behavioural Researchers on Asians) and cE-Bs (Centre for EnvironmentBehaviour Studies), Faculty of Architecture, Planning \& Surveying, Universiti Teknologi MARA, Malaysia.

https://doi.org/10.21834/aje-bs.v2i3.186 


\subsection{Introduction}

Nowadays, people spend less time in contact with nature than what was done a few decades ago and this change in lifestyle is negatively affecting our health as well as the natural world. This disconnection from nature and its negative consequences have been gathered by Louv (2005) in the term

"Nature Deficit Disorder" and, even though it is not a recognized illness, empirical evidence supports this idea. Following this line of research, the present investigation intends to study whether nearby nature, such as nature in the school area as well as in the home area, would have any benefits on children's psychological health.

\subsection{Literature Review}

With regards to children, several studies have proven that disconnection from the natural world negatively affects their physical (Ordemir \& Yilmaz, 2008) and mental health (Taylor, Kuo \& Sullivan, 2002) and, at the same time, reduces children's affinity towards the natural world (Wells \& Lekies, 2006). Some of these negative effects are a result of the lack of opportunities for psychological restoration that is usually supported by natural environments. It is well known that the natural world is the most suitable environment to recover from a task that requires attention (Kaplan \& Kaplan, 1989) and the evidence shows that spending time in nature is good for children's cognitive functioning (Well, 2000), nature helps children to cope with their problems, to think clearly and to feel free and relaxed (Korpela, Kytta \& Hartig, 2002), it decreases the symptoms of ADHD (Attention Deficit Hyperactivity Disorder) in children who suffer from this illness (Taylor \& Kuo, 2009) and for girls whose houses have views to natural elements, it increases their self-discipline (Taylor, Kuo \& Sullivan, 2002), among others.

Moreover, the nature buffering hypothesis argues that nature buffers the negative effects produced by stressful situations to which children are exposed. In other words, nature acts as an intermediary between two variables, in this case between the adverse situations to which children are exposed and the stress level that they suffer from that exposure (the negative effects).

The most relevant study done about the nature buffering hypothesis was carried out by Wells and Evans (2003) with a sample of rural children. The authors concluded that children who lived in more natural areas coped better with (and were less vulnerable to) adversity than those who did not have access to natural environments. Moreover, children who were more vulnerable - those who suffered stressful events more frequently - were the ones who benefited the most.

The aim of the present study is to evaluate whether the nearby nature existing in places where urban children spend their time (residential and school areas) moderates the effects produced by the stressful events children are exposed to. In order to study the nature buffering hypothesis, this research, as the one done by Wells and Evans (2003), is based 
on the Moderator Model of Baron and Kenny (1986). These authors claim that the moderator is a "qualitative (e.g., sex, race, class) or quantitative (e. g., level of reward) variable that affects the direction and/or the strength of the relation between an independent or predictor variable and a dependent or criterion variable". In the present study, the dependent variable or the outset is the children's stress level and the independent variable is the frequency of stressful events suffered by children, measured in an objective way.

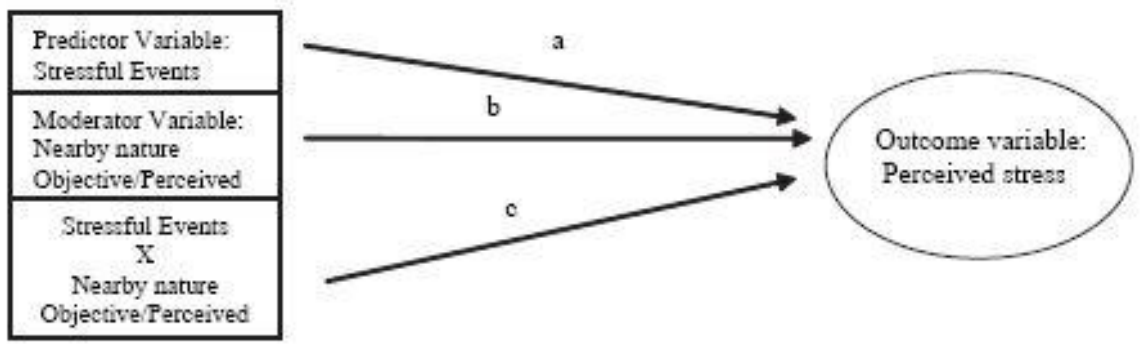

Figure 1: Moderator model. Adapted from Baron \& Kenny $(1986,1174)$. Source: Baron and Kenny. $(1986,1174)$

The moderator hypothesis is supported if the interaction (Path $\mathrm{c}$ ) is significant (Baron \& Kenny, 1986). There can also be significant effects for the predictor and the moderator (paths a and b), but they do not indicate a moderator effect.

The present research studies if there are any direct effects of nature - whether path $a$ is significant- or direct effects of the stressful events - whether path $b$ is significant - on the outset variable (perceived stress or stress level). Moreover, the possible moderator effect of nearby nature is studied, in other words, whether path $\mathrm{c}$ is significant.

The objectives of the investigation are mainly three-fold. First, to evaluate the positive effects that nearby nature has on children. Second, to get a better understanding of the nature buffering hypothesis. Third, to include for the first time in the study of the nature buffering hypothesis, nature in the school area as well as nature as perceived by children.

\subsection{Methodology}

\subsection{Participants}

The sample was formed with 172 children (53\% boys and $47 \%$ girls) aged 10 to 13 (M= $11.3 ; \mathrm{SD}=.673)$. 


\subsection{Instruments}

Nearby Nature Observational Scale (Collado, 2009): it registers the amount of nature children have access to by following an observational procedure. It is divided into two subscales that measure the amount of nature in the school area and the nature in the home area, including variables such as the amount of natural elements in the school playground, how natural the views are or the walking distance to the nearest park. Each of the variables of these subscales was given a score and with the final score the home areas and the school areas are divided into four groups: non natural, mixed, natural and very natural.

Perceived Stress Scale (Martorell, Sánchez, Miranda \& Escrivá, 1990). This instrument is formed with 50 items: 25 items are used to measure the stress level of the children, taking into consideration the stressful events registered in the home area and another 25 items register the stress level associated with stressful events in the school area. The final score indicates the stress level at home, in the school and the global score is the average between the 2 subscales.

Perceived Nature Questionnaire: it measures the perception of the child about the nearby nature in his or her surroundings, i.e.: "I think that my house is in a natural surrounding" or "I consider that the playground in my school is natural". The child can answer: 1 (not at all), 2 (yes, there is a bit of nature), 3 (yes, there is some nature) or 4 (There is a lot of nature).

The nature that people perceive has been used in previous studies as an indicator of the amount of nature existing in a place (Hur, Nasar \& Chun, 2010).

Stressful Events Questionnaire: it is based on the Stressful Events Repertoire of Lewis (Lewis, Seigel \& Lewis, 1984). Among the 20 stressful situations suggested by the authors, five have been described as being the main sources of psychological distress (not spending enough time with parents, parents arguing when the child is present, not having enough time to do their homework, having nothing to do and not having enough money to spend on what they want). These five situations were the ones used in this study. Participants were asked about the frequency of occurrence of each of these events in the last year (1, it never happened to me to 5 , it happened to me all the time). It needs to be stressed that this instrument is not a scale and that it is intended to collect data about the frequency of occurrence of each of the events. As Lewis et al. (1984) recommend, in this study each of the stressful events have been used individually. It could be considered that if the five stressful events occurred to a child at the same time he or she would be highly stressed, but that does not mean that frequent exposure to just one of them would produce less stress. 


\subsection{Procedure}

Data was collected in four primary schools chosen using the Nearby Nature Observational Scale. They were divided into four groups: very natural, natural, medium amount of nature - mixed school and non natural. All the self reported instruments were filled in by the children with the presence of one of the researchers and participants were asked for their addresses. All the houses were visited in order to register the amount of nature near the houses.

\subsection{Results and Discussions}

\subsection{Perceived nature, perceived stress and frequency of stressful events. Descriptive data}

The perceived nature in the four schools is statistically different $\left(F_{(125,730)}=3.17, p<.001\right)$ as well as the perceived stress level $\left(F_{(3,171)}=4.19, p<.01\right)$ (see Tables 1 and 2 ).

Table 1: Means and standard deviations for the nature perceived in each school and the stress level shown in each school.

\begin{tabular}{llllllllll} 
& \multicolumn{1}{c}{ Very natural } & \multicolumn{2}{c}{ Natural } & & Mixed & & Non natural \\
\hline & M & ST & M & ST & M & ST & M & ST \\
Nature Perceived in the schools & 4 & .00 & 3.22 & .66 & 2.88 & .73 & 1.75 & .60 \\
Stress Level in the school & 2.31 & .49 & 2.58 & .63 & 2.34 & .52 & 2.66 & 54 \\
\hline
\end{tabular}

Table 2: Student's t-test using perceived nature in the school and stress level in the school as dependent variables.

\begin{tabular}{lcccccc} 
& VN $-\mathrm{NN}$ & $\mathrm{VN}-\mathrm{M}$ & $\mathrm{VN}-\mathrm{N}$ & $\mathrm{N}-\mathrm{NN}$ & $\mathrm{N}-\mathrm{M}$ & $\mathrm{M}-\mathrm{NN}$ \\
\hline $\begin{array}{l}\mathrm{t} \text { student for } \\
\text { perceived } \\
\text { nature }\end{array}$ & $22.09^{* * *}$ & $-9.15^{* *}$ & $5.36^{* *}$ & $-14.56^{* *}$ & $-4.63^{* *}$ & $7.88^{* *}$ \\
$\begin{array}{l}t \text { student for } \\
\text { stress level }\end{array}$ & $-2.84^{* *}$ & $\begin{array}{c}\text { Non } \\
\text { significant } \\
\text { differences }\end{array}$ & $-2.13^{*}$ & $\begin{array}{c}\text { Non } \\
\text { significant } \\
\text { differences }\end{array}$ & $-1.99^{*}$ & $\begin{array}{c}\text { Non } \\
\text { significant } \\
\text { differences }\end{array}$ \\
\hline
\end{tabular}

$$
{ }^{* *} p<.01 ;{ }^{*} p<.05
$$

Note: $V N=$ Very natural; $N=$ natural; $M=$ Mixed and $N N=$ Non natural

Taking into account the frequency of exposure of the child to stressful events, the amount of times that children are exposed to the stressful event, not spending enough time with parents, changes significantly among the four schools, $\left.\left(F_{(3,170)}=6.12\right), p<.01\right)$. Children from the very natural school are the ones who suffer not spending time with their 
parents more frequently, $(M=2.94 ; S D=1.32)$ and children from the non natural school are the ones who spend more time with their parents, $(M=1.91$; $S D=1.16)$. See Figure 3.

There are also significant differences in the frequency of the stressful event, not having enough money to spend on what they want $\left(F_{(3,170)}=3.46, p<.05\right)$. However, the differences are not significant for any of the three other stressful events registered: not having enough time to do their homework, having nothing to do and parents arguing when the child is present.

\subsection{Relationship between the frequency of stressful events and nearby nature with the perceived stress level}

Variance analysis was carried out in order to check whether there is a relationship between the frequency of stressful events and the perceived stress level, taking the stress level as the dependent variable and the frequency of each of the stressful events as the factor. Results show that there are significant differences in children's stress levels according to the amount of time they are exposed to their parents arguments $\left(F_{(4,170)}=7.35 ; p<.01\right)$. In the same way, there are also significant differences in children's stress levels according to the frequency of the stressful event not having enough time to do their homework, $\left(F_{(4,170)}=\right.$ $3.45, p<.05)$ and also depending on the frequency of exposure to the stressful event not having enough money to spend on what they want, $\left.F_{(4,170)}=2.45, p<.05\right)$. It can be concluded that the stressful events have a direct effect on the perceived stress level.

At the same time, perceived nearby nature also affect children's stress levels directly. The Pearson correlations in Table 3 show that there is a significant negative correlation between the perceived nearby nature (at school and daily) and the nearby nature measured objectively (in the home area and global) and the stress level, so that the higher the amount of nature the lower the stress level. These results corroborate the idea that nearby nature has a direct positive effect on children's wellbeing. Moreover, the variance analysis show that children's stress level varies according to the amount of nature children perceive in the school $\left(F_{(3,170)}=4.07, p<.01\right)$. The amount of nature that a school has and the nature children perceive in the school influence students stress level.

Table 3: Correlation between nearby nature and perceived stress

\begin{tabular}{lclllll}
\hline & $\begin{array}{l}\text { Perceived nat } \\
\text { in the school }\end{array}$ & $\begin{array}{l}\text { Perceived nat } \\
\text { at home }\end{array}$ & $\begin{array}{l}\text { Daily perceived } \\
\text { nat }\end{array}$ & $\begin{array}{l}\text { Objective } \\
\text { nat in } \\
\text { school }\end{array}$ & $\begin{array}{l}\text { Objective } \\
\text { nat at } \\
\text { bome }\end{array}$ & $\begin{array}{l}\text { Daily } \\
\text { objective } \\
\text { nat }\end{array}$ \\
\hline $\begin{array}{l}\text { Average total } \\
\text { stress level }\end{array}$ & $-.302^{* *}$ & .070 & $-.155^{* *}$ & -.087 & -.087 & $-138^{*}$ \\
$\begin{array}{l}\text { Stress level in } \\
\text { the school }\end{array}$ & $-.196^{* *}$ & -.095 & -.009 & -.025 & $-.192^{* *}$ & -257 \\
\hline
\end{tabular}

${ }^{* *} p<.01 ;{ }^{*} p<.05$

Note: Nat $=$ Nature 


\subsection{Stress level according to nearby nature and the frequency of stressful events}

Nature buffering hypothesis suggests that nearby nature moderates the negative effect (perceived stress) produced by the stressful events so that children who have more nature around them suffer less stress than those who do not have nature in the surroundings, even when both groups of children are exposed to the same frequency of stressful events. One example of how the stress level diminishes in the presence of nature can be seen in Figure 2. There are four groups of children: the first two groups are children who suffer a low frequency of the stressful event not spending enough time with their parents and groups 3 and 4 are children who suffer a high frequency of this stressful event. As shown in Figure 4 , there are significant differences in the perceived stress level in the four groups, $F_{(3,123)}=$ $6.37, p<.01$. Moreover, the stress level is also different among those children who are exposed to the same frequency of stressful event.

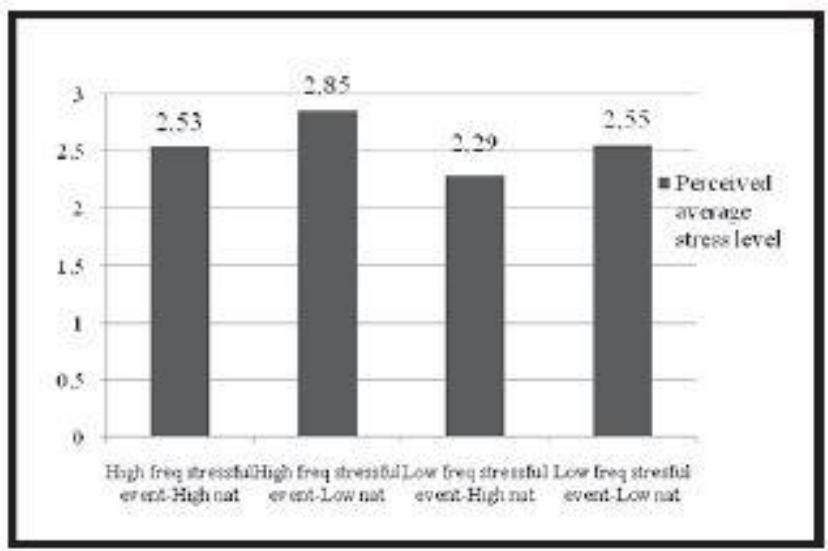

Figure 2: Perceived stress according to the interaction between not spending enough time with their parents and perceived nature in the school.

As it can be seen in Figure 4, the stress level of children from groups 1 and 2 is different, even though they are exposed to not spending time with their parents with the same frequency. These differences are significant $(t=-3.16, p<.05)$ meaning that children in group 2 show a higher stress level $(M=2.85$; $S D=.49)$ than children in group $1(M=$ 2.53; $\mathrm{SD}=.57)$. Moreover, the nature perceived in the school is different in these two groups, being higher in group $1(M=3.76 ; S D=.50)$ than in group $2(M=1.83 ; S D=.38)$. This difference is statistically significant $(t=14.00, p<.01)$. In the same way, it has been proven that there are significant differences in the perceived stress level of children in group $3(M=2.29 ; S D=.50)$ and $4(\mathrm{M}=2.55 ; \mathrm{SD}=.60)$, being $t=-2.46, p<.05$. The perceived nearby nature in the school area is also different in these two groups $(t=15.61, p<.01)$, the perceived nature being 
higher in group $3(M=3.53 ; S D=.55)$ than in group $4(M=1.70 ; S D=.46$; See Figure 4$)$. The combination of the other stressful events and the nearby nature brought similar results.

It can be concluded that children's stress level diminishes as the amount of nearby nature increases. However, even though a moderator effect can be foreseen, it cannot be assured that there is a moderator effect. In order to study the possible moderator effect, a new variable called Interaction between nature and the stressful event has been calculated, where each stressful event is each of the stressful event registered and where nature is each kind of measure of nature taken into consideration. For this study, the interaction variables that more significantly affect children's stress level have been chosen

\subsection{The moderator effect of nearby nature}

Using hierarchical regression analyses, the possible moderator effect of the different types of nature measured has been addressed. Four interaction effects were found significant. First of all, the stress level produced by the stressful events having nothing to do was moderated by the nature children perceive in their school, when the stress level at home and the stress level in the school were taken as dependent variables. As can be seen in Table 4, the effect of the perceived nature in the school is significant, $F(1,170)=49.51 ; p<.01$.

Table 4: Regression of children's stress level in the school onto perceived nature in the school, having nothing to do and interaction of perceived nature in the school $\mathrm{x}$ having nothing to do.

\begin{tabular}{|c|c|c|c|c|c|c|c|c|c|}
\hline Model & Predictor & Total $R^{2}$ & $\Delta R^{2}$ & $F\left(\Delta R^{2}\right)$ & df & b & $\mathrm{SEb}$ & $\beta$ & p \\
\hline Main effect & $\begin{array}{l}\text { Perc. Nat. } \\
\text { in the school }\end{array}$ & .226 & .226 & $49.514^{* *}$ & 1,170 & .238 & .034 & .475 & .000 \\
\hline Main effect & $\begin{array}{l}\text { Having } \\
\text { pothing } \\
\text { to do }\end{array}$ & .273 & .048 & $11.125^{* *}$ & 1,169 & -.110 & .033 & -.219 & .001 \\
\hline Interaction & $\begin{array}{l}\text { Perc uat. } \\
\text { in the school } \mathrm{x} \\
\text { baving nothing } \\
\text { to do }\end{array}$ & 309 & .036 & $8.737^{4 *}$ & 1.178 & .096 & .033 & .745 & .004 \\
\hline
\end{tabular}

${ }^{* *} p<.01 ;{ }^{*} p<.05$

Note: Perc. Nat. $=$ Perceived nature

This means that children who perceive more nature in their school area show a lower stress level than those whose school is non natural. The next line points out that the stress level is also influenced by having nothing to do and, therefore, those children who frequently experience having nothing to $d o$ are the ones who are more stressed, $F(1,169)=11.12 ; p<.01$. Finally, the last line represents the interaction between the perceived nearby nature in the school area and the stressful event. The interactioneffect is also statistically significant meaning that nearby nature in the school area moderates the stress produced by having nothing to do, $F(1,168)=8.73, p$ $<.001$. As it can be seen in Figure 5, there is an interaction effect represented by the union 
of both lines of the graph. According to Figure 5, when the frequency of the stressful event is low, the stress level shown by the children is low, being considerably low when the school playground is perceived as natural by the children. However, when the frequency of the stressful event is high the stress level is also high, even with the presence of nearby nature.

Similar results were obtained for the following interactions: 1) Interaction between perceived nature in the school and the stressful event having nothing to do, taking stress at home as the dependent variable. 2) Interaction between perceived nature in the home area and the stressful event parents arguing while the child is present, taking the stress at home as the dependent variable, and finally 3 ) Interaction between perceived nature in the school area and the stressful event not spending enough time with their parents, taking the global stress level as the dependent variable

\subsection{Conclusion}

Nearby nature moderates the negative effects produced by stressful events. In this way, those children who have more access to natural areas are able to cope better with stress and therefore their stress level is lower than it would be expected if nature was not acting as a protective factor. The impact of stressful events on children is weaker when the amount of nearby nature is higher.

In contrast to previous studies (Wells and Evans, 2003), the present investigation has taken into consideration not only the nearby nature measured in an objective way (with a scale) but also the moderator effect of the nature that children perceive. The data collected in this study shows that the perceived nature in the four schools is different and that the stress level of the children in each school also differs from one to another. It can be concluded that children in the very natural school are able to cope better with stress than children who attend classes in the non natural school, and this reinforces the importance that the amount of nature that children have in their school and its surroundings.

To sum up, four interaction effects found significant meaning that a moderator effect of nearby nature does exist. Low accessibility to the natural world, more frequent in today's society, negatively affects children's wellbeing and reduces their capacity to cope with adversity. With this, it can be concluded that including natural elements in home and school areas is important for children. Children's health and wellbeing depend on the way that these environments encourage children's contact with nature.

\section{Acknowledgement}

This research was conducted with support from the Spanish Ministry of Sciences and Innovation (PSI 2009-13422). 


\section{References}

Baron, R. M. and Kenny, D. A. (1986). The moderator-mediator variable distinction in social psychological research: Conceptual, strategic, and statistical consideration. Journal of Personality and Social Psychology, 51, 1173-1182.

Collado, S. (2009). La naturaleza cercana como moderadora del estrés infantil. Intermediate doctoral research (not published). Universidad Autónoma de Madrid.

Hur, M., Nasar J. and Chun, B. (2010). Neighborhood satisfaction, physical and perceived naturalness and openness. Journal of Environmental Psychology, 30, 52-59.

Kaplan, R.. and Kaplan, S. (1989). The experience of Nature. N. York: Cambridge University Press.

Korpela, K., Kytta, M. and Hartig, T. (2002). Restorative experience, self-regulation and children's place preferences. Journal of Environmental Psychology, 22, 387-398.

Lewis, C. E., Siegel, J. M., and Lewis, M. A. (1984). Feeling bad: Exploring sources of distress among preadolescent children. American Journal of Public Health, 74, 117-122.

Louv, R. (2005). The Last Child in the Woods. Saving our children from Nature- Deficit Disorder. Chapel Hill, NC: Algonquin Books.

Martorell, C., Sánchez, D., Miranda, A. and Escrivá, F. (1990). Evaluación del estrés en niños y adolescentes. Actas de II Congreso del Colegio Oficial de Psicólogos., Valencia: COP.

Ozdemir, A. and Yilmaz, O. (2008). Assessment of outdoor school environments and physical activity in Ankara's primary schools. Journal of Environmental Psychology, 28, 287-300.

Taylor, A., and Kuo, F.E. (2009). Children with attention deficits concentrate better after a walk in the park. Journal of Attention Disorders, 12, 402-409.

Taylor, A., Kuo, F. E. and Sullivan, W. C. (2002). Views of nature and self-discipline: Evidence from inner city children. Environment and Behaviour, 22, 49-63.

Wells, N. M. (2000). At home with nature: The effects of nearby nature on children's cognitive functioning. Environment and Behaviour, 32, 775-795.

Wells, N. M. and Evans, G. (2003). Nearby Nature. A buffer of life stress among rural children. Environment and Behaviour, 35, 311-330.

Wells, N.M. and Lekies, K. S. (2006). Nature and the life course: Pathway from childhood nature experiences to adult environmentalism. Children, Youth and Environments, 16, 1-24. 